\title{
The Research of the Relationship between Teachers and Students in the New Mode of Physical Education
}

\author{
Di-feng Fan ${ }^{*}$
}

Hainan College of Economics and Business, Haikou 571127, Hainan, China

\begin{abstract}
In the traditional teaching mode, teachers in order to establish the authority of the classroom, usually in front of the students showed severe image, this will enable students to have a psychological fear, this relationship will caused the gap between teachers and students and influence between teachers and students in the normal communication and students' healthy growth of teachers. We want to change the normal teacher-student interaction mode, so that teachers and students can be generated between the two-way communication, so that students in the physical and mental health development, learning in a happy environment. This paper expounds the concept of teacher-student interaction, according to the characteristics of physical education teachers and students, and puts forward the Countermeasures of the communication between teachers and students.
\end{abstract}

Keywords: Physical education, school-based web curriculum, teacher-student interaction.

\section{THE CONCEPT OF TEACHER-STUDENT INTER- ACTION}

Communication is a social relationship between people and communication between teachers and students is teachers and students for the realization of the goal of education, with its unique identity and status, through teaching and learning between the teachers and students exchange activities and the formation of nature, multiple teacher-student relationship $[1,2]$. From the perspective of sociology and pedagogy, the basic function of education is to construct a new harmonious relationship between teachers and students, so that students can grow up healthily in a harmonious and pleasant atmosphere. The relationship between teachers and students is not only the embodiment of the interpersonal relationship in education, but also a feature of the teaching management.

At present, there are a lot of research on the relationship between teachers and students in China and abroad, the research perspective and construction methods are not the same. The good relationship between teachers and students is the necessary guarantee for the success of school education activities, which is the consensus of all kinds of research, is the necessary conditions for the implementation of the new curriculum concept [3]. The essence of relationship between teachers and students is the school between teachers and students is the basic relationship between students and teachers, between teachers and students in cognition, emotion and behavior association as the main form of expression of the psychological relationship, reflect between teachers and students seek to satisfy its activity requires mental state [4-6]. In the educational activities of the emotional experience is also very important, the performance of students, happy, happy, satisfied, etc. Positive emotional experience has a positive effect on the communication between teachers and students.

The new teacher-student relationship requires that teachers and students can achieve the real equality of personality, in the interactive activities of democracy, in the atmosphere is harmonious. The core of it is the mutual acceptance of teachers and students, the mutual acceptance of attitude, the formation of a harmonious relationship between teachers and students, and to establish a harmonious relationship between teachers and students. Promote the new teacher-student relationship [7]. This is teachers' leading role in teaching. Therefore, every one of the teachers first to understand the new teaching idea, teaching change old ideas, freed from the authority of the "dignity of the teaching profession, put down the shelf, to understand the aspirations of students, from the command of teaching transformation as a guide, participants, from the decision to students what they should do and learn how to dominate change partners and students' cooperative learning.

Physical education teachers and students in the teaching and learning of educational exchanges, with a certain professional and educational, this kind of communication as a means of education can not only teach sports knowledge, skill and practice method, promote physical development of students, and can change the students' personality, teachers and students to promote the mutual understanding and exchange the views of teachers and students and views, promote friendship between students and teachers and emotional resonance. 


\section{CHARACTERISTICS OF PHYSICAL EDUCATION TEACHER-STUDENT INTERACTION}

\subsection{Physical Education Teachers and Students in Teach- ing and Learning Features}

Physical education teaching is a special teaching method. The teaching process is a kind of teaching, learning and practice. Students through the process of practice, not only to master of sports and health care knowledge, technology and skills, also make the physical and mental exercise and development [8]. This teaching, interaction of teaching mode, makes it easier for the students and teachers to be integrated. It also laid the foundation of communication between teachers and students. The harmonious development of the relationship between teachers and students in physical education, but some teachers are not good at using this resource [9]. For example, in the end of the lecture, the demonstration layout of the task, do not take the initiative to integrate into the students, as shown in Fig. (1).

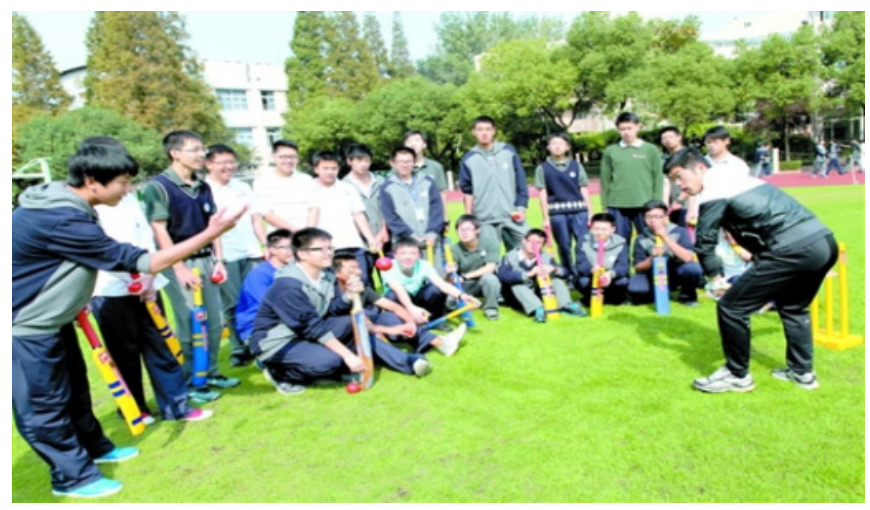

Fig. (1). Characteristics of physical education teacher-student interaction.

\subsection{The Teaching Environment of Physical Education is Beneficial to the Interaction between Teachers and Stu- dents}

The teaching process of physical education is the activity mode of physical exercises, which has a large outdoor space, fresh air, can reduce the psychological pressure of students, and the students' mind, so that students can be in a good mood. These is with one of the other class interaction between teachers and students in different conditions, physical education teachers in the teaching to make full use of outdoor teaching, for students to create a relaxed atmosphere in practice, to alleviate the psychological pressure of students, make students immerse themselves to their physical exercises, improve the classroom effect [10]. Secondly, physical education in the outdoor, teachers should pay special attention to their manners, use their own personality charm, to inspire students and teachers for students to produce a centripetal force, promote the development of the communication between teachers and students.

\subsection{The Characteristics of Communication between Stu- dents in Physical Education}

In physical education, there are not only the interaction between teachers and students, but also the communication between students and students, showing the diversity of stu- dents and teachers in physical education. Due to the physical education need to engage in all kinds of physical exercise and activities, students physical exercise requires both teachers' guidance and help, and the need to the mutual cooperation between the students, help each other, mutual evaluation and objective requirements interaction in many aspects. If it is said that in the other subjects of the classroom teaching is the main teacher and student exchange, then in the physical education class and the teacher's communication is more important. This communication is a process of communication. But it should be noted that in the classroom to improve the task of communication in a great extent, it is the responsibility of the teacher, not the students. Because physical education teachers in the teaching of physical education are to guide and participate in the role of physical education teachers in Physical Education in the guidance and participation, determine the degree of physical education teachers and students [11]. Physical education although there is a need for communication of teachers and students, students and students, this need accounted for a considerable position, but on the current situation in our city, is not enough to do this, also need to further improve. For example, most of the sports teachers in our city are aware of the students' main body status, and the teaching process is the students' activities, but neglect the co participation of teachers and students.

\section{TO IMPROVE THE EDUCATION COUNTERMEA- SURE OF SPORTS CLASS TEACHER-STUDENT IN- TERACTION}

If the school leadership to the school sports have enough attention; if the physical education teachers to conscientiously implement the new teaching concept, the concept of education, the view of teaching, have enough knowledge, constantly improve their knowledge level, improve their teaching ability and make full use of the characteristics of physical education teaching, then improve the normal development of the physical education teachers and students exchanges, it is not a problem.

\subsection{To Strengthen the Teaching Idea of Physical Educa- tion Teachers to Improve Teaching Ability}

Actively participate in various kinds of sports academic exchange activities, and other schools to carry out teaching experience, in the school sports teaching and research activities. Improve sports teaching idea of teachers, improve teachers' professional skills, and strengthen research on sports teaching idea, to improve the teaching ability, establish correct educational view, teaching view, student view, as shown in Fig. (2). School sports facilities, sports equipment to improve the quality of physical education.

In the new teaching mode, teachers and students through the activities of emotion, interest, ability of the psychological exchange, love is the bridge to establish a harmonious relationship between teachers and students, physical education teachers as long as the attention and care for students, can usher students respect [12]. Only relationship between teachers and students in love each other, each other equality and harmonious atmosphere, students can bluntly facing the teachers, boldly into the teaching activities, to experience, to achieve the teaching goal. New sports teaching mode to form 


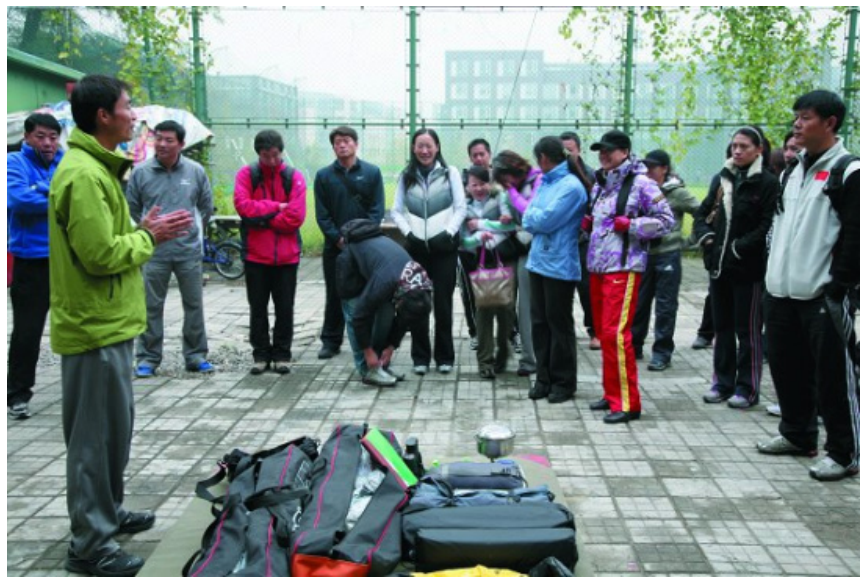

Fig. (2). Communication between teachers.

a harmonious relationship between teachers and students, it is necessary to communicate using a variety of methods, for example, in sports teaching in good use of praise and encouragement means, often with a heart to heart talk with students, often and students play, considerate and caring for students. At the same time, to give full play to the advantages of intuitive emotion in physical education. Such as rational use of body language, posture language in the establishment of harmonious relationship between teachers and students has a good effect, the eyes are the window to the soul, and the use of the eyes is to maintain the link and bridge of the harmonious relationship between teachers and students. And gestures can convey ideas, but also can express feelings, can increase the voice of the teacher to say a word of persuasion and appeal, efforts to improve the traditional impression of physical education teachers in the concept of students. Teachers only full of spirit, amiable, just for a moment to the students a sense of natural, lively, on the formation of the student's happy mood, the establishment of a harmonious relationship between teachers and students, is conducive to the formation of sports knowledge and skills of students. As long as we are teaching more smiles, more praise, showing the truth about caring teachers, will overcome the past students are afraid of is a physical education teacher for sports teachers "fierce" phenomenon, as long as they can establish a new, mutual respect, equal relationship between teachers and students, students can consciously and happy to accept the teacher, only then can arouse the students, the desire to consciously learn, ready to learn, so as to make them love sports, sports goal, the purpose of fitness to develop in an all-round way.

\subsection{To Change the Concept of Learning, to Cultivate the Students Will Quality}

Teachers should strengthen the students' ideological education, change the students' learning ideas, and cultivate their learning habits. In the process of PE teaching physical education teachers should not only pay great attention to the student learning, the development of the body, but also pay attention to the ideological education of the students, using good relationship between teachers and students affect students' learning behavior, change the concept of student learning. To cultivate students' good moral character and to establish the students' will to endure hardship. Using games, com- petitions and other teaching means to cultivate students help each other, mutual cooperation, the moral sentiments of friendship and unity; the games, endurance exercise, and other means to cultivate the quality of students will; use of the sports star to get successful material guide students endure hardship ahead spirit.

\subsection{To Establish a Fair and Reasonable Evaluation Mechanism for Physical Education}

"People-oriented, health first" the purpose of the physical education students in the autonomy, cooperation and inquiry learning in a comprehensive, free and harmonious development, this requires the establishment of a harmonious relationship between teachers and students in teaching [13]. Teachers in the teaching of assessment should adhere to the standards of diversity, through the evaluation of students to experience the joy of success, so as to stimulate students' learning interest and enthusiasm. Therefore in the evaluation of teachers is not the evaluation as a simple classification, sorting, and should respect students in the evaluation of individual differences to promote the healthy development of all students as the goal, put emphasis on the evaluation of the longitudinal evaluation, emphasis on students' progress and now compare, this paper argues that in practice in order to care for students' psychological requirements, building up students' self-confidence, appropriate to reduce the evaluation criteria, to break through the limitations of incubator. And some of the students' physical conditions themselves limit him in line with the evaluation criteria. At the same time, the students and the mutual evaluation into the evaluation, although students mutual evaluation is not accurate enough, but also reflects the mutual trust between teachers and students, but also between them and their evaluation of the level of emotional, and many other factors, the price, the student evaluation standards, teacher evaluation of peer assessment combined finally, comprehensive.

\section{STUDY OF SCHOOL-BASED WEB CURRICULUM}

\subsection{The Creation of Open Education Environment, Im- prove Students' Innovation Ability}

The development of middle school physical education and health school - based network curriculum emphasizes the diversity and dynamic of the development process, especially on the role of students' subject in the whole course of curriculum development. The curriculum requires the active participation of students in the whole process of curriculum development, and as a part of the curriculum evaluation of students. The students' ideas, the students mind flashes of wisdom, is the course material. Curriculum should not neglect the innovation of the students' knowledge of physical education and health, and the debate on the contents of the course. Since the innovation of students can be recognized and can be presented in the form of curriculum content, the students' innovation consciousness is greatly improved, so as to promote the improvement of students' innovation ability.

High school sports and Health School-based web curriculum development with emphasis on development of multiple subjects, students have access to the information related to the course is not only from the teacher, other teachers, curriculum experts and overseas students development main 
body is the information provider. So students will be exposed to multiple sports thought, multi sports, multiple fitness way, student's ideas will be opened, students' thinking will tend to live wave and avoid the rigid, the innovation ability of students will have a to improve the basic.

\subsection{Emphasizes Two-way Communication, to Ensure the Coordination Development of Teachers and Students in the Teaching Process}

Confucius as early as two thousand years ago proposed the "the educational idea of teaching benefits teachers as well as students". But this idea is not only in the modern school is not aware of the situation. Modern school by objectivism views of knowledge separates the relationship between teachers and students form into the view of teaching, students in a passive position, teachers become superior knowledge have [14]. Under the influence of China's exam oriented education, teachers' knowledge hegemony the utmost, resulting in further teachers and students of anthropogenic fragmentation, also this teacher above phenomenon in turn affect the teachers' further development, the teachers in this industry attraction decreased.

Middle school physical education teachers are the biggest victims of this concept. In sorrow is sad face few course teaching in the traditional high school physical education teachers to pay attention to is "with me", the students do the action must be and the teacher, the students can know its however, but not necessarily the so of course, and sports in the examination oriented education in a weak position, most of the students on the lack of understanding, so physical education teachers students questions. This is not only the students' physical education teachers, middle school physical education teachers on the job, are often difficult to find further learning motivation, not in the professional has further improved, in the work itself can not to meaning, thus affecting the sports teacher's own development.

High school sports and Health School-based web curriculum development advocate open individualized education and teaching ideas, breaking the imparting teaching thought bound to admit that sports and health knowledge of personal construct meaning, teachers and students of oneness and equality relations, encourage dialogue between teachers and students: pay attention to the role of teachers' personal experience in teaching, promote teachers' knowledge of personalized, requires teachers to constantly improve the professional level, so as to improve the PE Teachers' professional efficacy, to promote the common development of teachers and students, as shown in Fig. (3).

\subsection{Democratization of Teacher-student Relationship}

Openness and equality are the spirit of the Internet technology. School based network course is based on the course of the Internet era, is bound to reflect the spirit of the times. In the course of school based network curriculum, the equality and democracy of teacher-student relationship is the concrete embodiment of the spirit of the times. For example, the traditional school physical education, physical education teachers is a symbol of authority. Every physical education teacher will try to maintain its authority in the class, especially in the practice of physical education. Our sports prac-

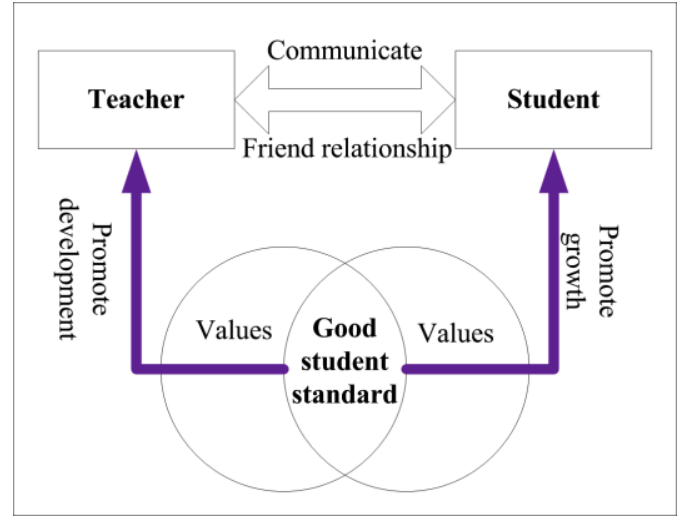

Fig. (3). The construction of harmonious relationship between teachers and students.

tice class sports teachers' imperative tone more prominent, deportment is majesty. Students in a passive and dependent position, students were asked to "with the teacher". These kind of traditional physical education teachers and student's relationship, the students' learning initiative and creativity, the full development of students become an empty talk [15]. The school based network course is from the curriculum development, to the implementation and evaluation of the curriculum, teachers and students are a kind of equality and dialogue relationship. In the course of the school, the teacher is no longer regarded as the only source of knowledge. Course for students provides a democratic and open learning environment, so that students can access to the Internet rich sports and health knowledge, the students with others outside the connection, of which there are sports and health professionals, they even than that of teachers and high many.

\section{CONCLUSION}

The emergence of the school based network curriculum has changed the traditional school knowledge distribution, and changed the relationship between teachers and students. It on the basis of the traditional teaching mode, let students better to accept a more professional, more comprehensive knowledge of sports and health, cultivate the students' sentiment, so that physical education teachers and students exchanges can be more healthy and reasonable, opening a new chapter for the education sector.

\section{CONFLICT OF INTEREST}

The author confirms that this article content has no conflict of interest.

\section{ACKNOWLEDGEMENTS}

Declared none.

\section{REFERENCES}

[1] Y.J. Shin, M. Miller-Day, J. Pettigrew, M.L. Hecht and J.L. Krieger, "Typology of delivery quality: latent profile analysis of teacher engagement and delivery techniques in a school-based prevention intervention, keepin'it REAL curriculum", Health Education Research, vol. 29, no. 6, pp. 897-905, 2014.

[2] D.A. Dudley, P. Pearson, A.D. Okely and W.G. Cotton, "Recommendations for policy and practice of physical education in culturally and linguistically diverse Australian secondary schools based 
on a two-year prospective cohort study", School Psychology International, vol. 36, no. 2, pp. 172-188, 2015.

[3] A.S. Ha, C. Lonsdale, J.Y.Y. Ng and D.R. Lubans, "A schoolbased rope skipping intervention for adolescents in Hong Kong: protocol of a matched-pair cluster randomized controlled trial", BMC Public Health, vol. 14, no. 1, p. 535, 2014.

[4] J. Jacobs and P. Wright, Social and Emotional Learning Policies and Physical Education, Column Editor: K.A.R. Richards, Strategies, vol. 27, no. 6, pp. 42-44, 2014

[5] C.J. Craig, J.A. You and S. Oh, "Tensions in teacher community: competing commitments in the teaching of US middle school physical education", Journal of Curriculum Studies, vol. 46, no. 5, pp. 697-728, 2014.

[6] K. Stenberg, L. Karlsson, H. Pitkaniemi and K. Maaranen, "Beginning student teachers' teacher identities based on their practical theories", European Journal of Teacher Education, vol. 37, no. 2, pp. 204-219, 2014.

[7] K. Mordal-Moen and K. Green, "Physical education teacher education in Norway: the perceptions of student teachers", Sport, Education and Society, vol. 19, no. 6, pp. 806-823, 2014.

[8] K.L. Bierman, R.L. Nix, C.E. Domitrovich and S. Gill, “"'Promoting academic and social-emotional school readiness: The Head Start REDI program", Child Development, vol. 79, no. 6, pp.18021817,2008

[9] S.E. Rimm-Kaufman, A.E. Baroody, R.A.A. Larsen, T.W. Curby and T. Abry, "To what extent do teacher-student interaction quality and student gender contribute to fifth graders' engagement in mathematics learning?", Journal of Educational Psychology, vol. 107 , no. 1, p. 170,2015

[10] A. Hawkins, C.R. Graham, R.R. Sudweeks and M.K. Barbour, "Academic performance, course completion rates, and student perception of the quality and frequency of interaction in a virtual high school", Distance Education, vol. 34, no. 1, pp. 64-83, 2013.

[11] D.A. Dudley, A.D. Okely, P. Pearson and W.G. Cotton, "Decline in enjoyment of physical education among culturally and linguistically diverse youth", International Journal of Quantitative Research in Education, vol. 1, no. 4, pp. 408-425, 2013.

[12] S. Oh, J.A. You, W. Kim and C.J. Craig, "What spurs curriculum making in physical education? Four narratives of experienced teachers", Sport, Education and Society, vol. 18, no. 2, pp. 243266, 2013.

[13] A. Wrench, C. Hammond, F. McCallum and D. Price, "Inspire to aspire: raising aspirational outcomes through a student well-being curricular focus", International Journal of Inclusive Education, vol. 17, no. 9, pp. 932-947, 2013

[14] M. Cochran-Smith, A.M. Villegas, L. Abrams, L. Chavez-Moreno, T. Mills and R. Stern, "Critiquing Teacher Preparation Research An Overview of the Field, Part II", Journal of Teacher Education, vol. 66, no. 2, pp. 109-121, 2015.

[15] J. Ullman, "Ladylike/butch, sporty/dapper: exploring 'gender climate'with Australian LGBTQ students using stage-environment fit theory", Sex Education, vol. 14, no. 4, pp. 430-443, 2014.

Received: June 10, 2015

Revised: July 29, 2015

Accepted: August 15, 2015

(C) Di-feng Fan; Licensee Bentham Open.

This is an open access article licensed under the terms of the (https://creativecommons.org/licenses/by/4.0/legalcode), which permits unrestricted, noncommercial use, distribution and reproduction in any medium, provided the work is properly cited. 